\title{
New spectroscopic data of erbium ions in GaN thin films
}

\author{
F. Pellé ${ }^{\text {a,*}}$, F. Auzel ${ }^{\text {a }}$, J.M. Zavada ${ }^{\text {b. D.S. Lee }}{ }^{\text {c }}$, A.J. Steckl ${ }^{\text {c }}$ \\ a UMR7574-CNRS 1, Place Aristide Briand, F-92195 Meudon cedex, France \\ ${ }^{\mathrm{b}}$ US Army Research Office, Electronics Division, Durham, NC 27709, USA \\ ${ }^{c}$ University of Cincinnati, Nanoelectronics Laboratory, Cincinnati, OH 45221, USA
}

\begin{abstract}
Optical properties of erbium ions in MBE-grown GaN-thin films are reported. Three types of sites were identified using site selective laser excitation. The main center is ascribed to the $\mathrm{Er}^{3+}$ ions substituted in the Ga sub-lattice while the two other centers are assigned to Er-related defects. The lifetimes of the ${ }^{4} \mathrm{~S}_{3 / 2}$ and ${ }^{4} \mathrm{I}_{13 / 2}$ multiplets of the main center are strongly quenched with increasing Er concentration. The complex decay profile of the visible fluorescence and its concentration dependence were modeled and interpreted using the diffusion-limited model. The dynamics of the infrared emission at $1.54 \mu \mathrm{m}$ from the ${ }^{4} \mathrm{I}_{13 / 2}$ multiplet after excitation in the visible range is discussed. The crystal field strength of $\mathrm{Er}^{3+}$ in $\mathrm{GaN}$ was deduced from the overall crystal field splitting of the ground multiplet. Comparison of the results with those obtained in inorganic materials indicates that the rare earth is well embedded in the semiconductor host and not in a impurity oxide phase.
\end{abstract}

(C) 2003 Elsevier B.V. All rights reserved.

Keywords: Rare earth; GaN; Luminescence; Spectroscopy

\section{Introduction}

Visible emission of the $\mathrm{RE}^{3+}$ ions in Wide Band Gap Semiconductors (WBGS) are being intensively investigated. Among the wide-bandgap semiconductors, III-V nitrides seem to be the most promising host materials for $\mathrm{RE}^{3+}$ doping due to their energy band gap, which makes them transparent to the visible emission of $\mathrm{RE}^{3+}$. Being chemically and thermally stable too, they are good candidates for optoelectronic and photonic applications. $\mathrm{GaN}$ is the most popular and new methods of synthesis (MOCVD and SSMBE) have allowed an increase in the incorporation of $\mathrm{RE}^{3+}$ into this material. Recent results obtained for $\mathrm{RE}^{3+}$-doped $\mathrm{GaN}$ are very promising since $\mathrm{GaN}$ doped with $\mathrm{Eu}^{3+}, \mathrm{Tm}^{3+}$ and $\mathrm{Er}^{3+}$ have been used to realize full-color electroluminescent devices [1]. Despite several studies of the spectroscopic properties of different $\mathrm{RE}^{3+}$ ions in $\mathrm{GaN}$ thin films, no clear correlation between the efficiency of the visible $\mathrm{RE}^{3+}$ luminescence and the interaction of $\mathrm{RE}^{3+}$ with the host has been established [2-4]. A complete understanding of the spectroscopic properties of the RE dopants in the semiconductor (excitation schemes and luminescence effi-

\footnotetext{
* Corresponding author. Tel.: +33-1450-75593; fax: +33-1450-75107.

E-mail address: pelle@cnrs-bellevue.fr (F. Pellé).
}

ciency) and their relationship to growth processes is needed in order to improve the performance of current $\mathrm{RE}^{3+}$ doped $\mathrm{GaN}$ devices. In this paper, new results on the spectroscopic analysis of the $\mathrm{Er}^{3+}$ ions in $\mathrm{GaN}$ thin films are presented.

\section{Experimental}

The GaN: $\mathrm{Er}^{3+}$ thin films were grown using the Solid State Solid Source Molecular Beam Epitaxy (SSMBE) method on a p-type (1 111 ) Si substrate after deposition of an AlN buffer layer. The complete synthetic procedure is described in [5]. The $\mathrm{Er}^{3+}$ concentration of the $\mathrm{GaN}: \mathrm{Er}^{3+}$ thin films, measured with Rutherford Backscattering Spectroscopy (RBS) and Secondary Ion Mass Spectroscopy (SIMS), ranges from 0.025 up to 11.2 at. \% .

The $\mathrm{Er}^{3+}$ luminescence was excited either by an OPO pumped by the third harmonic of a pulsed Nd:YAG laser (501-DNS,720 BM Industrie) or by the $\mathrm{Ar}^{+}$lines at 514.5 and $496.5 \mathrm{~nm}$ (Coherent Innova 300). The luminescence was dispersed through a HR460 Jobin-Yvon monochromator and detected by a EMI 9558 QBM photomultiplier in the visible range and by a InGaAs (Hamamatsu) photodiode for the IR luminescence. Time resolved spectra and fluorescence 
transients were digitized and averaged by an oscilloscope (TDS350 Tektronix) with data acquisition on a PC. Low temperature measurements were performed by cooling the samples in a closed-cycle CTI cooling system.

\section{Photoluminescence properties}

\subsection{Luminescence at room temperature}

Excitation of the $\mathrm{Er}^{3+}$ ions within the GaN band gap (to the ${ }^{4} \mathrm{~F}_{7 / 2}$ or ${ }^{2} \mathrm{H}_{11 / 2}$ multiplets) yields a luminescence spectrum dominated at room temperature by emission in the visible range. This is easily assigned to radiative transitions from the ${ }^{2} \mathrm{H}_{11 / 2}$ and ${ }^{4} \mathrm{~S}_{3 / 2}$ multiplets to the ground state one. Weak transitions from the lower multiplets $\left({ }^{4} \mathrm{~F}_{9 / 2},{ }^{4} \mathrm{I}_{9 / 2}\right.$, ${ }^{4} I_{13 / 2}$ ) are observed, too (Fig. 1). Emission from the ${ }^{4} I_{13 / 2}$ multiplet shows a rather high efficiency compared to that observed from the ${ }^{4} \mathrm{~F}_{9 / 2}$ and ${ }^{4} \mathrm{I}_{9 / 2}$ multiplets. No significant changes in the luminescence are observed with increasing $\mathrm{Er}^{3+}$ concentration and the luminescence from the ${ }^{4} \mathrm{~S}_{3 / 2}$ and ${ }^{4} \mathrm{I}_{13 / 2}$ multiplets have the same behavior with a maximum intensity at about 1 at.\% in both cases. Non-exponential decay and the concentration dependence of the ${ }^{4} \mathrm{~S}_{3 / 2}$ emission indicate that the optical relaxation involves energy transfer between adjacent $\mathrm{Er}^{3+}$ ions (Fig. 2).

\subsection{Infrared emission: selective excitation}

The selective excitation spectra at low temperature $(T=$ $10 \mathrm{~K}$ ) were analyzed monitoring the ${ }^{4} \mathrm{I}_{13 / 2} \rightarrow{ }^{4} \mathrm{I}_{15 / 2}$ main emission lines (Fig. 3a). The most intense lines at 1531 and $1537 \mathrm{~nm}$ are observed only when excited in the ${ }^{2} \mathrm{H}_{11 / 2}$ multiplet (Fig. 3b) The two other lines at 1545 and $1552 \mathrm{~nm}$ are only weakly excited from the ${ }^{2} \mathrm{H}_{11 / 2}$ multiplet but another

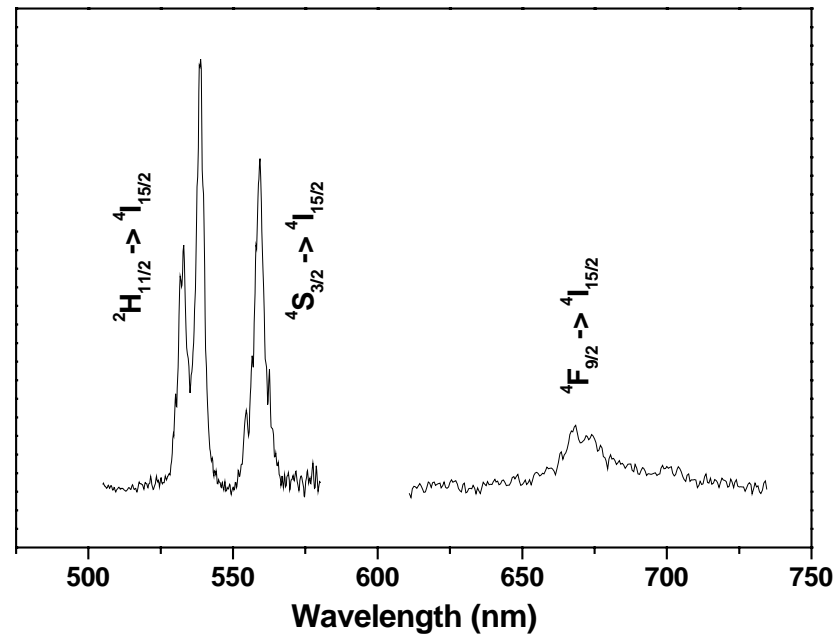

Fig. 1. Visible fluorescence spectrum of $\mathrm{GaN}: \mathrm{Er}^{3+}(0.17$ at.\%) recorded at room temperature under resonant excitation in the ${ }^{4} \mathrm{~F}_{7 / 2}$ multiplet $\left(\lambda_{\text {excitation }}=498 \mathrm{~nm}\right)$.

efficient excitation line is observed at 515.7 and $518 \mathrm{~nm}$, respectively. These lines fall off the resonance with the intraconfigurational $4 \mathrm{f}$ transitions of $\mathrm{Er}^{3+}$ (Fig. 3b). The three different infrared emission spectra recorded with selective excitation (Fig. 3a) were ascribed to different emitting centers labeled as $\mathrm{C} 1, \mathrm{C} 2$ and $\mathrm{C} 3$. Selective excitation into the two lines observed around $516 \mathrm{~nm}$ provides emission of one order of magnitude higher intensity than when excited into the intra configuration $4 \mathrm{f}$ transitions. In these cases, the luminescence is mainly due to the transition between the lowest levels of the ${ }^{4} I_{13 / 2}$ and ${ }^{4} I_{15 / 2}$ manifolds. The transitions to other Stark components of the ground state being very weak, a complete analysis of the level schemes cannot be performed. The emission spectrum and its temporal behavior strongly depend on the excitation wavelength. Furthermore,

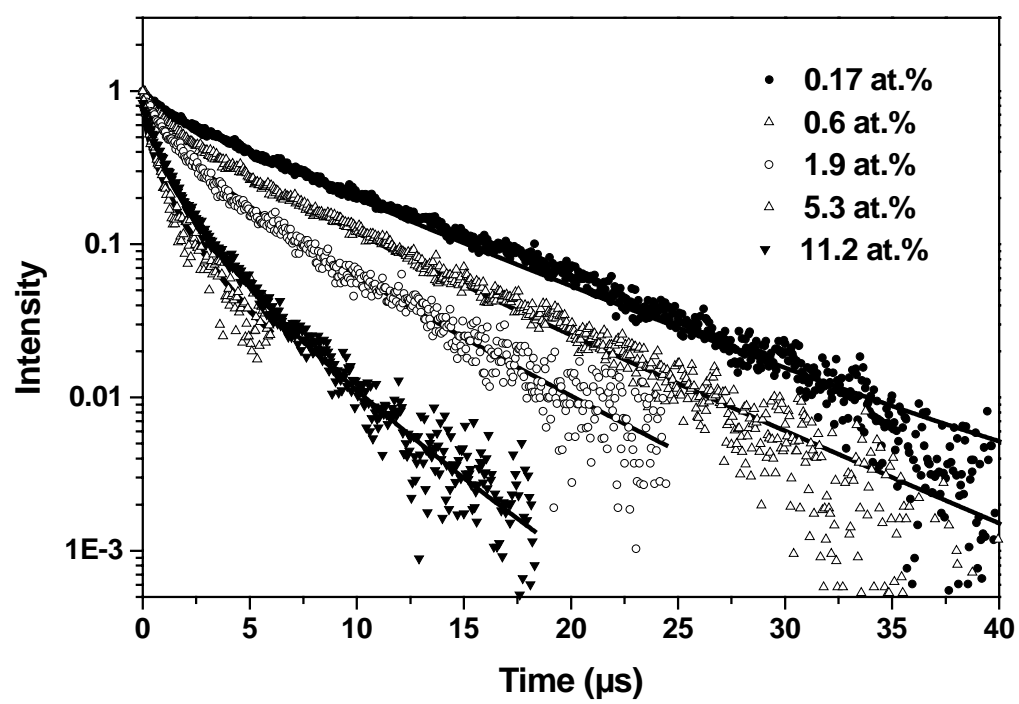

Fig. $2 .{ }^{4} \mathrm{~S}_{3 / 2}$ decay profile as a function of $\mathrm{Er}^{3+}$ concentration $(T=300 \mathrm{~K})$ (symbols: experimental data; full lines: theoretical curves calculated using Eq. (1). 

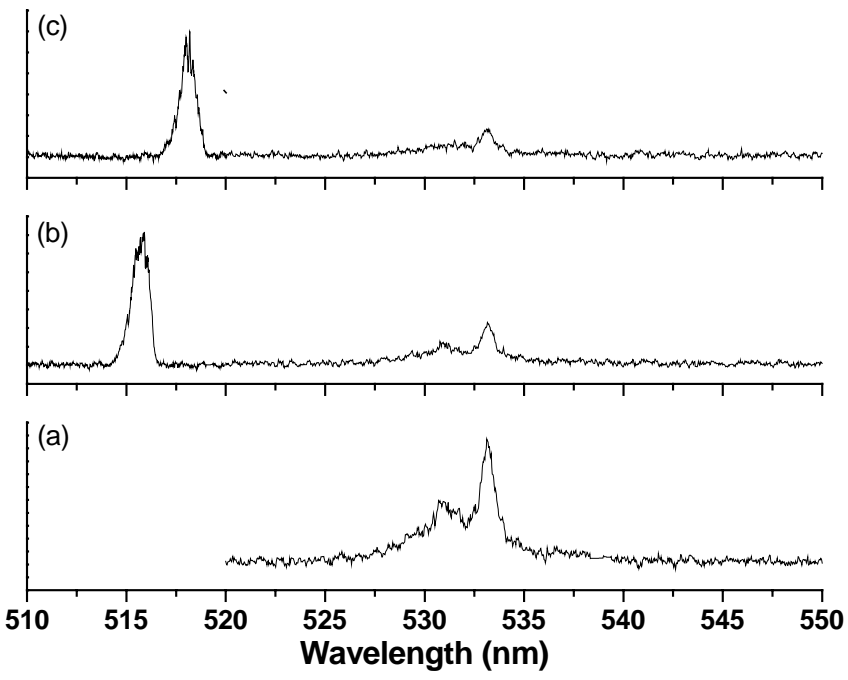
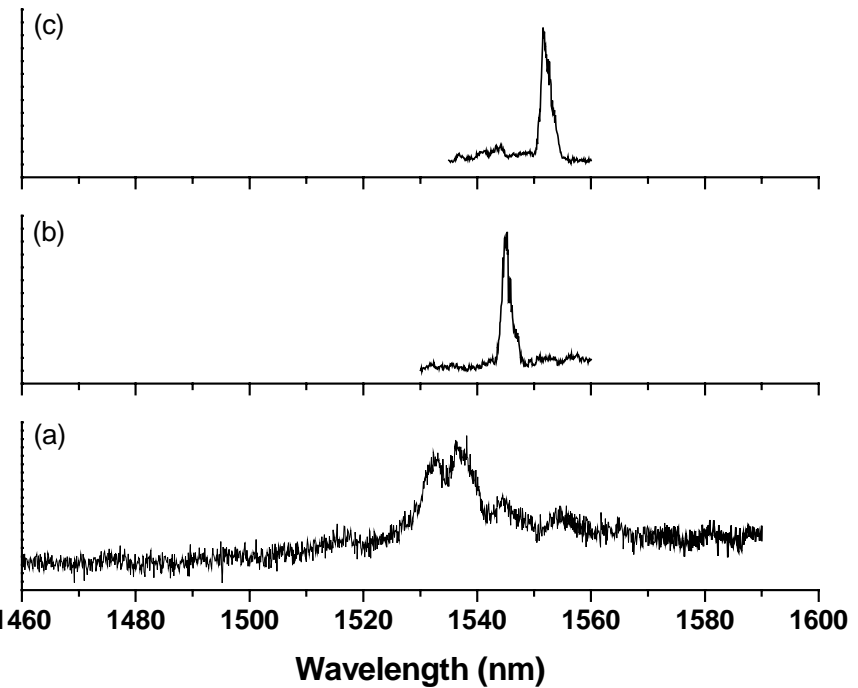

Fig. 3. (A) Selective excitation spectrum of the ${ }^{4} \mathrm{I}_{13 / 2} \rightarrow{ }^{4} \mathrm{I}_{15 / 2}$ transition recorded at $10 \mathrm{~K}$ for $\mathrm{GaN}: \mathrm{Er}^{3+}$ (0.6 at.\%): (a) $\lambda_{\text {analysis }}=1537 \mathrm{~nm}$; (b) $\lambda_{\text {analysis }}=1545 \mathrm{~nm}$; (c) $\lambda_{\text {analysis }}=1552 \mathrm{~nm}$. (B) ${ }^{4} \mathrm{I}_{13 / 2} \rightarrow{ }^{4} \mathrm{I}_{15 / 2}$ fluorescence spectrum recorded at $10 \mathrm{~K}$ for GaN:Er ${ }^{3+}(0.6$ at.\%) with selective excitation: (a) $\lambda_{\text {excitation }}=533.7 \mathrm{~nm}$; (b) $\lambda_{\text {excitation }}=515.7 \mathrm{~nm}$; () $\lambda_{\text {excitation }}=518 \mathrm{~nm}$.

Table 1

${ }^{4} \mathrm{I}_{13 / 2}$ rise and decay times measured at $10 \mathrm{~K}$ for the different centers (GaN: 0.6 at. $\% \mathrm{Er}^{3+}$ )

\begin{tabular}{llll}
\hline & $\lambda_{\text {excitation }}(\mathrm{nm})$ & Rise time $(\mu \mathrm{s})$ & Decay time $(\mathrm{ms})$ \\
\hline $\mathrm{C} 1$ & 533.7 & 862 & 3.1 \\
$\mathrm{C} 2$ & 515.7 & 64.5 & 1.718 \\
$\mathrm{C} 3$ & 518 & 79 & 1.773 \\
\hline
\end{tabular}

with increasing temperature, the intensity of the $\mathrm{C} 2$ and $\mathrm{C} 3$ luminescence decreases greatly and cannot be recorded.

The luminescence intensity of the selectively excited ${ }^{4} \mathrm{I}_{13 / 2}$ multiplet as a function of time (Fig. 4) shows that the time constants of the excitation as well as the decay processes for center $\mathrm{C} 1$ are much longer than those for $\mathrm{C} 2$ and $\mathrm{C} 3$. These processes have been modeled using a simple model with a rise $\left(\tau_{\mathrm{r}}\right)$ and exponential decay $\left(\tau_{\mathrm{d}}\right)$. The time constants deduced from the theoretical fit of the experimental curves (Table 1) indicate that the processes involved in the population and de-excitation of the ${ }^{4} \mathrm{I}_{13 / 2}$ multiplet of centers $\mathrm{C} 2$ and $\mathrm{C} 3$ are quite identical. This indicates a similar environment of the $\mathrm{Er}^{3+}$ ions in $\mathrm{C} 2$ and $\mathrm{C} 3$.

The luminescence decay curves of the ${ }^{4} \mathrm{I}_{13 / 2}$ multiplet for the center $\mathrm{C} 1$ measured at room temperature as a function of $\mathrm{Er}^{3+}$ concentration reveal that the both decay and rise times

Table 2

${ }^{4} \mathrm{I}_{13 / 2}$ rise and decay times measured at room temperature as a function of $\mathrm{Er}^{3+}$ concentration $\left(\lambda_{\text {excitation }}=533.7 \mathrm{~nm}\right.$, analysis for center $\mathrm{C} 1$ at $\lambda_{\text {analysis }}=1537 \mathrm{~nm}$ )

\begin{tabular}{lll}
\hline$\left[\mathrm{Er}^{3+}\right]($ at. $\%)$ & Rise time $(\mu \mathrm{s})$ & Decay time $(\mathrm{ms})$ \\
\hline 0.17 & 98 & 2.43 \\
0.6 & 33.6 & 1.41 \\
1.9 & 21 & 0.310 \\
\hline
\end{tabular}

(Table 2) are strongly reduced with increasing $\mathrm{Er}^{3+}$ content as a consequence of $\mathrm{Er}^{3+}-\mathrm{Er}^{3+}$ interactions.

\section{Identification of the emitting centers}

The occurrence of several centers for $\mathrm{Er}^{3+}$ ions and excitation of the ${ }^{4} \mathrm{I}_{13 / 2}$ multiplet within the GaN band gap and out of the absorption range of the $\mathrm{Er}^{3+}\left({ }^{2 S+1} L_{\mathrm{J}}\right)$ states of the $4 \mathrm{f}^{11}$ configuration has already been reported for the Er-implanted GaN thin films [6,7]. The excitation spectrum consisted of an unstructured broad band extending from 460 to $530 \mathrm{~nm}$. The present additional excitation lines are well within this broad band and the shape of the $\mathrm{C} 2$ and $\mathrm{C} 3$ emission spectra are very similar to those in [6]. The doping by implantation [6] causes damage in the $\mathrm{GaN}$ lattice that cannot be completely removed by annealing. A high concentration of defects or the presence of extended defects is expected in the implanted samples. This may explain the broad band observed previously when compared to the present samples obtained by MBE in which the defects should be more localized, giving rise to discrete spectra. The luminescence intensity obtained by the non-intraconfigurational $4 \mathrm{f}$ excitation is of an order of magnitude more intense than that recorded with resonant $4 \mathrm{f}-4 \mathrm{f}$ excitation ([6] and this work). The high efficiency of the extra excitation and the very low absorption cross sections of the intra-configurational 4f transitions suggest that the excitation of the $\mathrm{C} 2$ and $\mathrm{C} 3$ centers proceeds by an $\mathrm{Er}^{3+}$ trap-related absorption rather than via $4 \mathrm{f}-4 \mathrm{f}$ transitions of $\mathrm{Er}^{3+}$. No visible or infrared emission from these centers was recorded with direct excitation in the $4 \mathrm{f}-4 \mathrm{f}$ transitions. Despite lower infrared emission intensity for $\mathrm{C} 1$, this center can be directly excited by the very weak $4 \mathrm{f}-4 \mathrm{f}$ transitions. The concentration of 


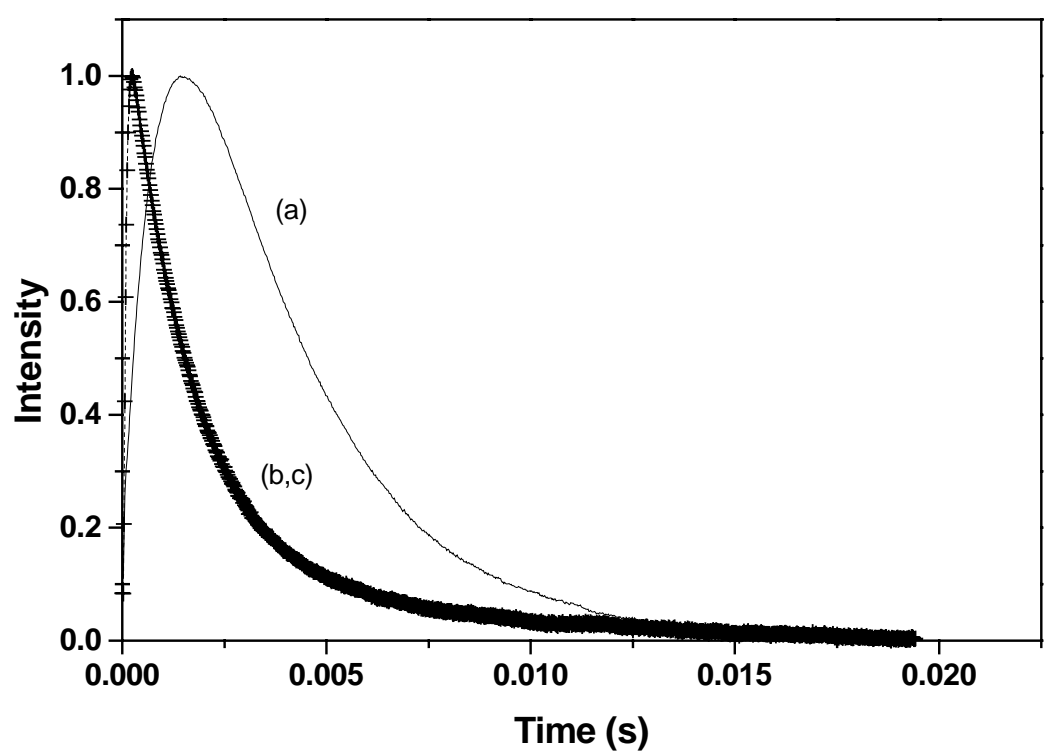

Fig. $4 .{ }^{4} \mathrm{I}_{13 / 2}$ decay profile as a function of excitation wavelength recorded at $10 \mathrm{~K}$ : (a) $\lambda_{\text {excitation }}=533.7 \mathrm{~nm}$ and $\lambda_{\text {analysis }}=1537 \mathrm{~nm}$ corresponding to $\mathrm{C} 1$; (b) $\lambda_{\text {excitation }}=515.7 \mathrm{~nm}$ and: $\lambda_{\text {analysis }}=1545 \mathrm{~nm}$ corresponding to $\mathrm{C} 2$; $\odot \lambda_{\text {excitation }}=518 \mathrm{~nm}$ and $\lambda_{\text {analysis }}=1552 \mathrm{~nm}$ corresponding to $\mathrm{C} 3$ (full line: theoretical fit; cross: experimental curves).

the $\mathrm{C} 2$ and $\mathrm{C} 3$ centers must thus be much lower than that of $\mathrm{C} 1$.

The non-exponential time dependence and the concentration dependence of the visible luminescence suggest an important contribution from the $\mathrm{Er}^{3+}-\mathrm{Er}^{3+}$ interactions to the de-excitation process for the center $\mathrm{C} 1$. Based on RBS analyses it was found that a great majority $(\approx 95 \%)$ of the $\mathrm{Er}^{3+}$ ions occupies substitutional sites in the Ga sublattice even at relatively high $\mathrm{Er}^{3+}$ concentration [8]. At very high $\mathrm{Er}^{3+}$ concentration, a pure ErN phase is obtained as shown by XRD demonstrating also the clustering of $\mathrm{Er}^{3+}$ in $\mathrm{GaN}$ [5]. The concentration quenching of the lifetime (Fig. 3) indicates that a cluster formation is present even at low $\mathrm{Er}^{3+}$ concentrations. Based on the spectroscopic data and the XRD patterns as a function of the $\mathrm{Er}^{3+}$ content, the $\mathrm{C} 1$ center is ascribed to the $\mathrm{Er}^{3+}$ ions in the regular $\mathrm{Ga}$ site. The $\mathrm{C} 2$ and $\mathrm{C} 3$ centers can be attributed to $\mathrm{Er}^{3+}$ ions in interstitial positions near defects produced by introducing the dopants into the lattice, as observed for other $\mathrm{RE}^{3+}$ doped semiconductors. $\mathrm{RE}^{3+}$ induced levels in the band gap and their role in the excitation process have already been shown for InP: $\mathrm{Yb}^{3+}$ [9], GaAs: $\mathrm{Er}^{3+}$ [10] and $\mathrm{Er}^{3+}: \mathrm{Si}$ [11].

\section{Luminescence dynamics}

\subsection{Visible emission of the Cl center}

The $\mathrm{C} 1$ center can be considered as the main center. The time dependence of the ${ }^{4} \mathrm{~S}_{3 / 2} \rightarrow{ }^{4} \mathrm{I}_{15 / 2}$ luminescence at room temperature deviates from a simple exponential behavior irrespective of the $\mathrm{Er}^{3+}$ concentration (Fig. 3). For low $\mathrm{Er}^{3+}$ concentrations, the decay profile can be fitted to two exponential functions explained by the presence of two $\mathrm{Er}^{3+}$ sites. For high $\mathrm{Er}^{3+}$ concentrations, the experimental decay curves cannot be fitted by only two exponentials indicating that other processes such as energy transfer and/or diffusion are involved. The deviation from the simple exponential law in the initial part of the decay increases with increasing $\mathrm{Er}^{3+}$ concentration. The long part of the decay follows an exponential behavior with a time constant which gradually decreases with increasing the $\mathrm{Er}^{3+}$ concentration. For even higher $\mathrm{Er}^{3+}$ concentrations, the overall decay of the ${ }^{4} S_{3 / 2}$ luminescence becomes faster and approaches to a single exponential decay (Fig. 2). The ion-ion interactions should be taken into account to explain the decay profile and the strong decrease in the decay time with increasing $\mathrm{Er}^{3+}$ concentration. Since no impurity has been detected, $\mathrm{Er}^{3+}$ will be considered as both a sensitizer and an activator. From the concentration dependence of the asymptotic decay, the experimental decay curves were interpreted according to the diffusion limited model. A general solution has been obtained for the sensitizer decay function including diffusion within the sensitizer system and sensitizer-acceptor energy transfer via a dipole-dipole coupling [12]:

$$
\begin{aligned}
I(t)= & I(0) \exp \left[-\frac{t}{\tau_{0}}-\frac{4 \pi^{3 / 2}}{3} N_{\mathrm{A}}\left(\alpha_{\mathrm{SA}} t\right)^{1 / 2}\right. \\
& \left.\times\left(\frac{1+10.87 x+15.50 x^{2}}{1+8.743 x}\right)^{3 / 4}\right]
\end{aligned}
$$

where $x=D \alpha_{\mathrm{SA}}^{-1 / 3} t^{2 / 3}$, with $D$ and $N_{\mathrm{A}}$ the diffusion constant and the acceptor concentration, respectively and $\alpha_{\mathrm{SA}}$ is related to the sensitizer-acceptor interaction. The calculations are described in detail elsewhere [13]. All the microscopic parameters characterizing the $\mathrm{Er}^{3+}-\mathrm{Er}^{3+}$ interaction 
in different $\mathrm{GaN}$ samples were determined. The calculated curves using Eq. (1) agree well with the experimental data.

\subsection{Infrared emission}

The complex decay behavior of the visible emission allows one to deduce the strong $\mathrm{Er}^{3+}-\mathrm{Er}^{3+}$ interactions for $\mathrm{C} 1$. Because of the weak intensity of the transitions from levels between the excited multiplet $\left({ }^{4} S_{3 / 2}\right)$ and ${ }^{4} I_{13 / 2}$, the multiphonon relaxation process seems not very efficient. The population of the ${ }^{4} \mathrm{I}_{13 / 2}$ multiplet of $\mathrm{C} 1$ can be explained by a cross relaxation process which overcomes the multiphonon relaxation. The first step of the relaxation of the visible excitation proposed is the $\left({ }^{4} \mathrm{~S}_{3 / 2},{ }^{4} \mathrm{I}_{15 / 2}\right) \rightarrow\left({ }^{4} \mathrm{I}_{11 / 2},{ }^{4} \mathrm{I}_{13 / 2}\right)$ cross relaxation after a migration of the excitation within the ${ }^{4} \mathrm{~S}_{3 / 2}$ multiplet. In a second step, the ${ }^{4} \mathrm{I}_{13 / 2}$ multiplet is populated by the ${ }^{4} \mathrm{I}_{11 / 2} \rightarrow{ }^{4} \mathrm{I}_{13 / 2}$ radiative transition since at $10 \mathrm{~K}$ the probability of the ${ }^{4} \mathrm{I}_{11 / 2} \rightarrow{ }^{4} \mathrm{I}_{13 / 2}$ multiphonon process is very low.

The process populating the emitting ${ }^{4} \mathrm{I}_{13 / 2}$ level of the $\mathrm{C} 2$ and $\mathrm{C} 3$ centers is faster, but a similar cross relaxation process between the related trap excited level and the ${ }^{4} \mathrm{I}_{13 / 2}$ level is proposed. This can explain why no emission from the ${ }^{4} S_{3 / 2}$ level can be observed.

\subsection{Self quenching of the infrared emission of $\mathrm{Cl}$ center}

The quenching of the infrared emission with increasing $\mathrm{Er}^{3+}$ concentration (Table 2) cannot be due to a cross relaxation process, since the ${ }^{4} \mathrm{I}_{13 / 2}$ emitting state is the first excited state. However, the self-quenching behavior is still well described by a limited diffusion process [14]. The quenching centers are most probably the $\mathrm{C} 2, \mathrm{C} 3$ centers which levels are at energy below that of $\mathrm{C} 1$. The corresponding intrinsic decay $\tau_{0}\left({ }^{4} \mathrm{I}_{13 / 2}\right)$ was found to be $2.48 \mathrm{~ms}$, and the critical concentration $\mathrm{N}_{0}$ equal to $0.67 \times 10^{21} \mathrm{~cm}^{-3}(0.8$ at. \%).

The quantum efficiency of the infrared emission was estimated by comparison with the results obtained for a fluoride glass using the same phonon cut-off frequency and similar crystal field strength. After correction for the index of refraction, the quantum efficiency for the $1.5 \mu \mathrm{m}$ emission was found to be 77 and $62.5 \%$ at low temperature and at room temperature, respectively. The energy transfer to free carriers could explain the lower quantum efficiency in $\mathrm{GaN}$ than in an insulator such as YAG.

\section{Crystal field strength analysis}

Based on the emission spectra recorded for different $\mathrm{C} 1$ excited multiplets, the energies of the Stark components and the overall splitting of the ground multiplet were deduced. From the overall splitting of the $4 \mathrm{f}^{\mathrm{N}}$ multiplets, it is possible to deduce the crystal field (CF) strength using a scalar field parameter $N_{v}$ which allows a convenient comparison between different host materials [15]. The overall splitting of the ground ${ }^{4} \mathrm{I}_{15 / 2}$ multiplet $\left(299 \mathrm{~cm}^{-1}\right)$ gives $1557 \mathrm{~cm}^{-1}$ for the $N_{\mathrm{v}}$ value that is between those for $\mathrm{CsCdBr}_{3}$ and $\mathrm{LiYF}_{4}$ known as materials with weak crystal field. Calculation of the $\mathrm{CF}$ strength expected for $\mathrm{Nd}^{3+}$ (no reliable $N_{\mathrm{v}}$ values are available for $\mathrm{Er}^{3+}$ ) is possible by taking into account the lanthanide contraction [16]. The $\mathrm{N}_{\mathrm{v}}\left(\mathrm{Nd}^{3+}\right)$ value for $\mathrm{GaN}\left(2139 \mathrm{~cm}^{-1}\right)$ is between those for $\mathrm{LaCl}_{3}\left(1062 \mathrm{~cm}^{-1}\right)$ and $\mathrm{LaF}_{3}\left(2356 \mathrm{~cm}^{-1}\right)$. The $\mathrm{CF}$ strength in $\mathrm{GaN}$ is much weaker than in oxides for which the $N_{\mathrm{v}}$ value is larger than $3000 \mathrm{~cm}^{-1}$ [17]. This indicates that the rare earth is well imbedded in the semiconductor host and not in an impurity oxide phase. On the other hand, a comparison to the results for GaAs: $\mathrm{Er}^{3+}$ [17], the overall splitting for ${ }^{4} \mathrm{I}_{13 / 2}\left(353 \mathrm{~cm}^{-1}\right)$ in $\mathrm{GaAs}$ would give a much higher $N_{\mathrm{v}}$ value $\left(2504 \mathrm{~cm}^{-1}\right)$ in agreement with oxygen surrounding the $\mathrm{Er}^{3+}$ [18]. Since $N_{\mathrm{v}}$ for $\mathrm{Er}^{3+}$ in GaN is clearly lower than that for GaAs or the oxide hosts, the present results suggest the substitution of $\mathrm{Ga}^{3+}$ by $\mathrm{Er}^{3+}$.

Another way to verify this hypothesis is to study the nephelauxetic red shift [19] of the ${ }^{4} \mathrm{I}_{13 / 2} \rightarrow{ }^{4} \mathrm{I}_{15 / 2}$ transition barycenter at $1.5 \mu \mathrm{m}$ for various $\mathrm{Er}^{3+}$ doped materials available in the literature data $[18,20,21]$. The barycenter ${ }^{4} \mathrm{I}_{13 / 2} \rightarrow 4 \mathrm{I}_{15 / 2}$ value $\left(6462 \mathrm{~cm}^{-1}\right)$ for $\mathrm{GaN}$ is between those for YAG and $\mathrm{CsCdBr}_{3}$ which corresponds to a covalent surrounding for $\mathrm{R}^{3+}$ ions. The electronic environment of $\mathrm{Er}^{3+}$ in $\mathrm{GaN}$ is thus rather covalent. As a conclusion, a comparison with the results for GaAs centers with oxygen and with strong crystal field, the $\mathrm{C}_{1}$ main center in $\mathrm{GaN}$ shows a typical behavior to be expected for a $\mathrm{Ga}$ site with covalent bonding to nitrogen: a weak crystal field and a large nephelauxetic red shift.

\section{Conclusions}

Based on site-selective excitation spectroscopy, three kinds of sites were identified for the $\mathrm{Er}^{3+}$ ions in $\mathrm{GaN}$. The main center was concluded to be Er located on the $\mathrm{Ga}$ site. The majority of the $\mathrm{Er}^{3+}$ ions are in this center. The two other sites were assigned to $\mathrm{Er}^{3+}$-related defects and ascribed to $\mathrm{Er}^{3+}$ species in interstitial positions. A non-exponential decay profile and the concentration dependence of the ${ }^{4} \mathrm{~S}_{3 / 2}$ luminescence for the main center indicate that the optical relaxation involves energy transfer processes between adjacent $\mathrm{Er}^{3+}$ ions. The luminescence decay curves were modeled and interpreted using a diffusion-limited migration of the optical excitation. All the microscopic parameters characterizing the interaction were determined and compared to the experimental data. The quenching of the infrared luminescence is found to occur due to the same process. Acceptors could be identified as centers ascribed to $\mathrm{Er}^{3+}$ in interstitial positions. The crystal field strength parameter was calculated for $\mathrm{Er}^{3+}$ in the main center and compared to that in other inorganic materials. The results confirm the substitution of the rare earth ion in 
the semiconductor crystal excluding oxygen environment. This is supported by the covalent character of the bonding of $\mathrm{Er}^{3+}$ to nitrogen for the main center.

\section{Acknowledgements}

This material is based upon work partially supported by the European Research Office of the US Army under contract No N62558-02-M-5113. Mrs Gardant is acknowledged for her assistance.

\section{References}

[1] D.S. Lee, J. Heikenfeld, R. Birkhahn, M. Garter, B.K. Lee, A.J. Steckl, Appl. Phys. Lett. 76 (2000) 1525.

[2] U. Hömmerich, J.T. Seo, J.D. MacKenzie, C.R. Abernathy, R. Birkhahn, A.J. Steckl, J.M. Zavada, in: Proceedings of MRS Fall 1999 Meeting, MRS Internet J. Nitride Semicond. Res. 5S1, W11.65 (2000).

[3] U. Hömmerich, J.T. Seo, M. Thaik, J.D. MacKenzie, C.R. Abernathy, S.J. Pearton, R.G. Wilson, J.M. Zavada, Internet J. Nitride Semicond. Res. 4S1 (1999) G11.6.

[4] A.J. Steckl, R. Birkhahn, Appl. Phys. Lett. 73 (1998) 1702.
[5] D.S. Lee, J. Heikenfeld, A.J. Steckl, U. Hömmerich, J.T. Seo, A. Braud, J.M. Zavada, Appl. Phys. Lett. 79 (2001) 719.

[6] H. Przybyliñska, A. Kozanecki, V. Glukhanyuk, W. Jantsch, D.J. As, K. Lischka, Physica B 308 (2001) 34.

[7] T. Monteiro, J. Soares, E. Alves, J. Appl. Phys. 89 (2001) 6183.

[8] K. Lorenz, R. Vianden, R.H. Birkhahn, A.J. Steckl, M.F. Da Silva, J.C. Soares, E. Alves, Nucl. Instr. Meth. B 161/163 (2000) 946.

[9] K. Takahei, A. Taguchi, H. Nakagome, K. Uwai, P.S. Whitney, J. Appl. Phys. 66 (1989) 4941.

[10] R.A. Hogg, K. Takahei, A. Taguchi, Phys. Rev. B 56 (1997) 10255.

[11] F.P. Widdershoven, J.P.M. Naus, Mater. Sci. Eng. B 4 (1989) 71.

[12] M. Yokota, O. Tanimoto, J. Phys. Soc. Japan 22 (1967) 779.

[13] F. Pellé, F. Auzel, J.M. Zavada, U. Hömmerich, D.S. Lee, A.J. Steckl, Nato Sciences Series, NATO Sciences Series II: Mathematics, Physics and Chemistry, vol 126, 1 (2003).

[14] F. Auzel, F. Bonfigli, S. Gagliari, G. Baldacchini, J. Lumin. 94-95 (2001) 293.

[15] F. Auzel, O. Malta, J. Phys. (Fr.) 44 (1983) 201.

[16] F. Auzel, Opt. Mater. 19 (2002) 89.

[17] E. Antic-Fidancev, J. Hölsä, M. Lastusaari, A. Lupei, Phys. Rev. B 64 (2001) 195108.

[18] H. Hennen, J. Schneider, G. Pomerenke, P.C. Becker, Appl. Phys. Lett. 43 (1983) 943.

[19] C.K. Jorgensen, Prog. Inorg. Chem. 4 (1962) 73.

[20] A.A. Kaminskii, Laser Crystals: Their physics and properties, Springer, Berlin, 1990

[21] N.J. Cockroft, G.D. Jones, R.W.G. Syme, J. Lumin. 43 (1989) 275. 